\title{
De novo arteriovenous malformation in a patient with hereditary hemorrhagic telangiectasia
}

\author{
Yusuke Shimoda, MD, ${ }^{1}$ Toshiya Osanai, MD, PhD, ${ }^{1}$ Naoki Nakayama, MD, PhD, ${ }^{1}$ \\ Satoshi Ushikoshi, MD, PhD, ${ }^{2}$ Masaaki Hokari, MD, PhD, ${ }^{1}$ Hideo Shichinohe, MD, PhD, ${ }^{1}$ \\ Takeo Abumiya, MD, PhD, ${ }^{1}$ Ken Kazumata, MD, PhD, ${ }^{1}$ and Kiyohiro Houkin, MD, PhD ${ }^{1}$

\begin{abstract}
1Department of Neurosurgery, Hokkaido University Graduate School of Medicine; and 2Department of Neurosurgery, Hokkaido Medical Center, Sapporo, Hokkaido, Japan
\end{abstract}

\begin{abstract}
Hereditary hemorrhagic telangiectasia $(\mathrm{HHT})$ is an autosomal dominant systemic disorder characterized by the enlargement of capillaries, recurrent nosebleeds, and multiple arteriovenous malformations (AVMs). Although cerebral AVMs are traditionally considered to be congenital lesions, some reports have described de novo AVMs, which suggests that the authors believed them to be dynamic conditions. In this article, the authors describe the case of a 5-year-old boy with HHT in whom a de novo cerebral AVM was detected after a negative MRI result at 5 months. To the authors' knowledge, this is the first report of a de novo AVM in a patient with HHT. In patients with a family history of HHT, de novo AVMs are possible, even when no lesions are detected at the first screening. Therefore, regular screenings need to be performed, and the family should be informed that AVMs could still develop despite normal MRI results.
\end{abstract}

http://thejns.org/doi/abs/10.3171/2015.7.PEDS15245

KEY WORDS hereditary hemorrhagic telangiectasia; de novo arteriovenous malformation; Rendu-Osler-Weber syndrome; vascular disorders

$\mathrm{H}$ EREDITARY hemorrhagic telangiectasia (HHT), known as Rendu-Osler-Weber syndrome, is an autosomal dominant vascular dysplasia. It is characterized by the enlargement of capillary vessels, repeated nosebleeds, and multisystemic arteriovenous malformations (AVMs) of the lung, liver, brain, and spinal cord. The incidence of HHT is approximately 1 per 100,000 people, of whom $3.7 \%-11 \%$ develop cerebral AVMs.,20 However, central nervous system complications occur in $48 \%$ of all patients with HHT because of paradoxical, air, or septic embolism and in 22\%-28\% because of cerebral AVMs. ${ }^{5,734}$ Cerebral AVMs either enlarge or regress during follow-up, and they occasionally recur after complete resection or radiation therapy. ${ }^{29}$

The pathogenesis of cerebral AVMs is not fully understood. They are believed to develop due to trauma, infection, radiation therapy, or congenital maldevelopment during Weeks 4-8 of embryonic development; thus, the traditional view has been that de novo AVMs do not exist. However, recent advancements in diagnostic techniques, such as MRI, have led to some reports of de novo
AVMs. ${ }^{4,533}$ However, MRI has also failed to detect AVMs on initial scans because of vasospasms or compressions caused by the mass effect of a hematoma or infarction.

Here, we report the case of a 5-year-old child with an AVM that was detected after a headache despite normal MRI results in his infancy. This is a rare case of de novo AVM without an accompanying mass effect. To the best of our knowledge, this is the first report of de novo AVM formation in a patient with HHT.

\section{Case Report}

History and Examination

A 5-year-old boy presented with no significant medical history, and a diagnosis of AVM was made. His mother and older brother both had HHT; his mother had undergone surgery for the resection of a cerebral AVM,,$^{35}$ and his brother had suffered from tetraplegia caused by an AVM of the cervical spinal cord. ${ }^{31}$ Based on his family history, he had also undergone screening MRI at 5 months of age, which revealed no lesions of the brain or spinal cord

ABBREVIATIONS AVM = arteriovenous malformation; DSA = digital subtraction angiography; $\mathrm{HHT}=$ hereditary hemorrhagic telangiectasia; $\mathrm{VEGF}=$ vascular endothelial growth factor.

SUBMITTED April 21, 2015. ACCEPTED July 24, 2015.

INCLUDE WHEN CITING Published online November 27, 2015; DOI: 10.3171/2015.7.PEDS15245. 

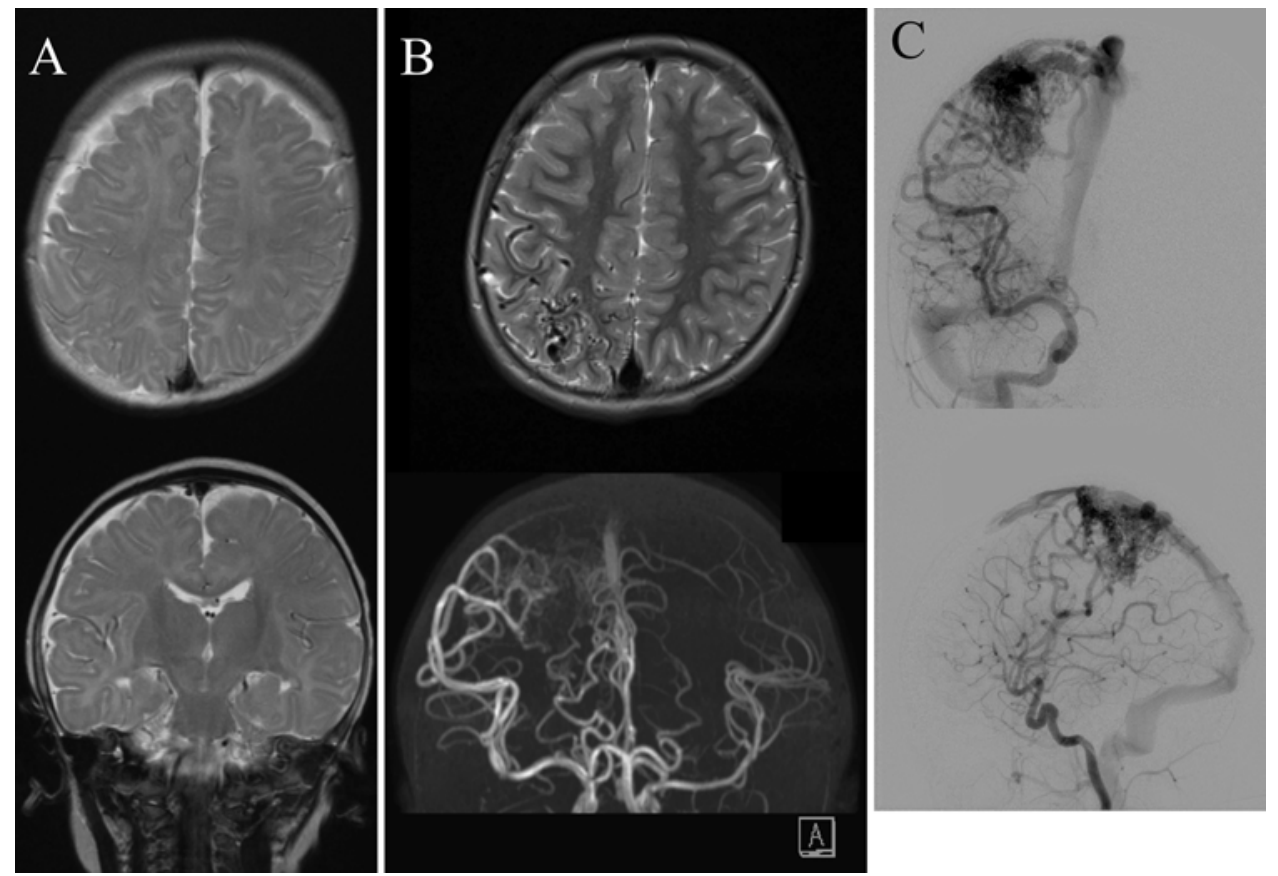

FIG. 1. MR images of the patient at 5 months and 5 years of age. A: Axial T2-weighted MR images at 5 months of age showing no structural vascular abnormality. B: MR image and angiogram at 5 years of age revealing abnormal vascular structures in the right parietal lobe. C: Anteroposterior (upper) and lateral (lower) internal carotid artery injection DSA image demonstrating an AVM recorded as Spetzler-Martin Grade 3 (size 2, eloquent 1, drainer 0).

(Fig. 1A). He had no medical problems except recurrent nosebleeds. At 5 years of age, he suffered from a transient thunderclap headache. Repeat MRI at this presentation revealed an abnormal signal void in the right parietal lobe (Fig. 1B), and cerebral digital subtraction angiography (DSA) revealed a nidus with the predominant arterial supply from the right middle cerebral artery (Fig. 1C). A diagnosis of HHT was made on the basis of family history, recurrent nosebleeds, and evidence of a cerebral AVM; no genetic diagnosis was made (Table 1).

\section{Operation and Postoperative Course}

Surgery was performed to eliminate the future risk of hemorrhage. The lesion was resected after copolymer (Onyx) embolization of the 2 arterial feeders (Fig. 2A and B). Subsequent postoperative imaging showed edema around the cavity (Fig. 3). The patient's initial left-sided hemiparesis was successfully managed by rehabilitation; he made a full recovery and was discharged with no neurological deficits. Follow-up DSA after 1 month also showed no residual lesion or recurrence (Fig. 2C).

\section{TABLE 1. Diagnostic criteria for $H \mathrm{HT}^{*}$}

\begin{tabular}{l}
\hline Nosebleeds (spontaneous \& recurrent) \\
\hline Mucocutaneous telangiectases (multiple \& characteristic sites [i.e., \\
lips, oral cavity, \& fingers]) \\
AVM (pulmonary, cerebral, hepatic, spinal, gastrointestinal, \&/or \\
pancreatic) \\
Family history of a first-degree relative in whom HHT has been \\
diagnosed
\end{tabular}

\footnotetext{
${ }^{*}$ A definitive diagnosis is made when 3 or more criteria are met, and possible or suspected diagnosis is made when 2 findings are present.
}

The diagnosis of AVM was confirmed by pathological examination. $\mathrm{H}$ \& $\mathrm{E}$ staining showed various sizes of vascular structures, including thrombosed vessels. With elastica-Masson and elastica-van Gieson staining, the internal elastic lamina was seen to be poorly formed, and immunohistochemistry showed that vascular endothelial growth factor (VEGF) was localized to the perivasculature. The pathological findings were therefore typical of AVM (Fig. 4).

\section{Discussion}

HHT is a systemic genetic disorder, and $3.7 \%-11 \%$ of people affected develop cerebral AVMs. Cerebral AVM is believed to be a dynamic rather than a static condition. Two genes have been shown to be responsible for the development of vascular malformations: the endoglin gene $(E N G)$, which is associated with a severe type of HHT (HHT1), ${ }^{21}$ and the activin receptor-like kinase Type 1 $(A L K-1)$ gene, which is associated with a less severe type (HHT2). ${ }^{12}$ Both genes block the formation of vascular intima, which results in pathological vascular formations. ${ }^{12,21}$ ENG, a transforming growth factor $\beta$-binding protein, was considered responsible for the dysfunction in tissue repair, angiogenesis, and preservation of vascular structures.

The incidence of cerebral AVMs in children with HHT is unknown. However, MRI is probably an adequate tool for screening. To date, the estimated frequencies of cerebral AVMs have been based on case reports and small series.

In 2006, Giordano et al. ${ }^{8}$ reported that the incidence of occult AVM was $12 \%$ in the first-ever cohort of children 


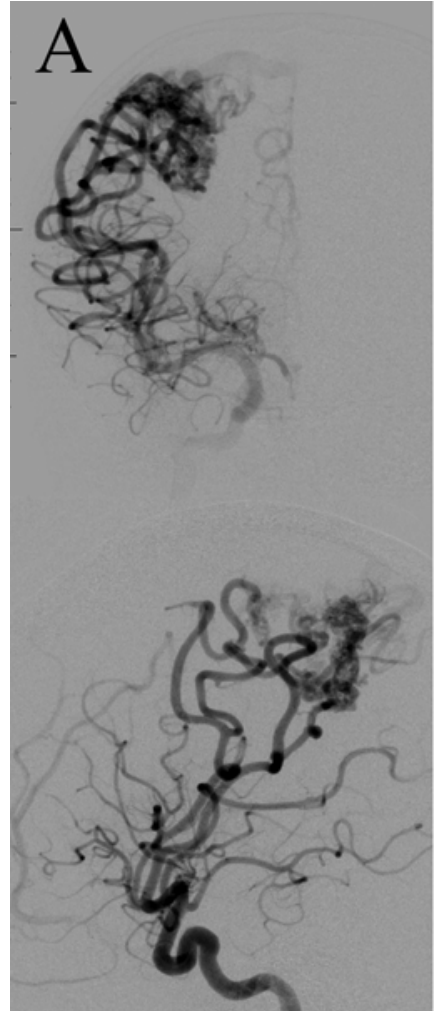

pre-ONYX

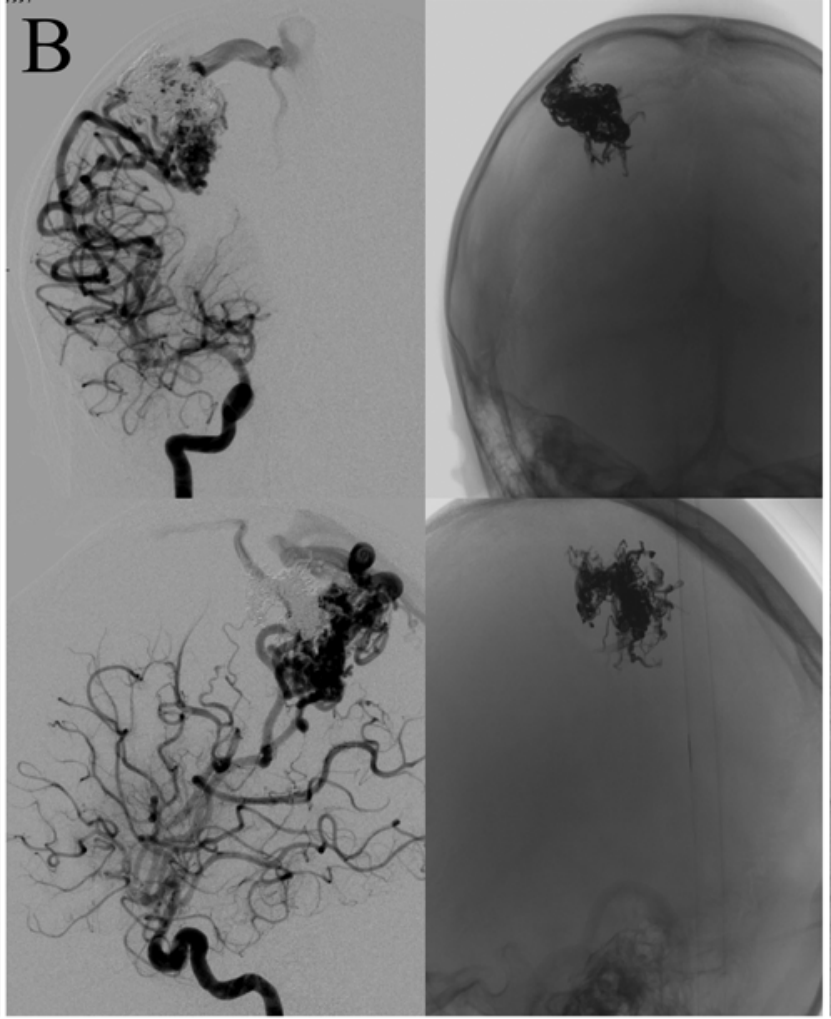

post-ONYX

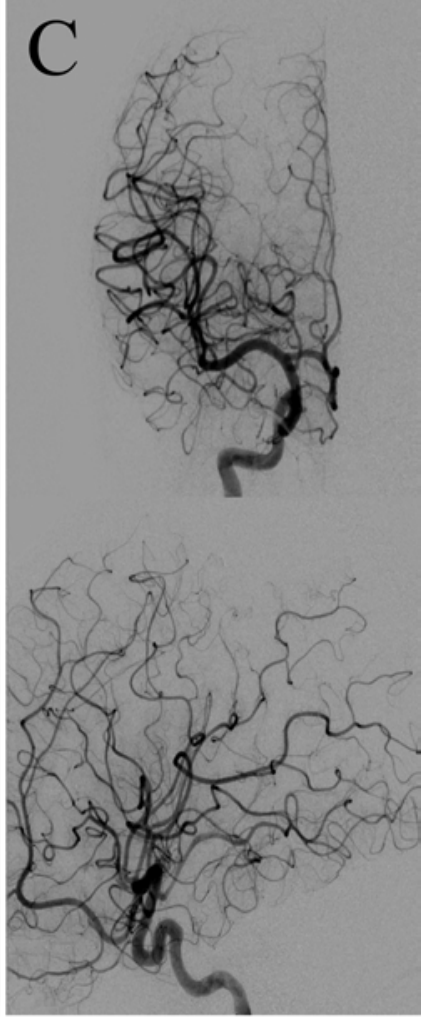

post-OP

FIG. 2. A: Preembolization angiograms, anteroposterior (upper) and lateral (lower) right internal carotid artery views. B: Postembolization radiographs of the skull showing Onyx cast, as well as postembolization angiograms, anteroposterior (upper) and lateral (lower) right internal carotid artery views. C: Postoperative DSA images showing gross-total removal of the nidus, anteroposterior (upper) and lateral (lower) right internal carotid artery views.

in whom it was diagnosed genetically and for whom there was a familial history of HHT. In a sample of 184 consecutive patients with HHT, Fulbright et al. ${ }^{7}$ found 42 cases of cerebral AVM, which suggests a prevalence rate of $23 \%$. However, they included $56(30 \%)$ patients in whom noncontrast MRI was performed, which they accepted as a limitation because it precluded the detection of subtle lesions that could have underestimated the prevalence. AlSaleh et al. ${ }^{2}$ reported that among symptomatic children with HHT, 5 (24\%) of 21 exhibited cerebral AVM.
A previous report stated that de novo AVMs occurred around VEGF-producing tumors, ${ }^{10}$ whereas another report stated that multisystemic nidi in an HHT mouse model were expanded in size postnatally after exposure to VEGF-rich conditions such as ischemia, inflammation, and wound healing. ${ }^{37}$ Thus, there is a close connection between VEGF and HHT. Furthermore, in HHT-associated cerebral AVMs, characteristic findings include small size, multiple locations, cortical lesions, and single drainages. ${ }^{18}$ Thus, we believe that, considering data from this
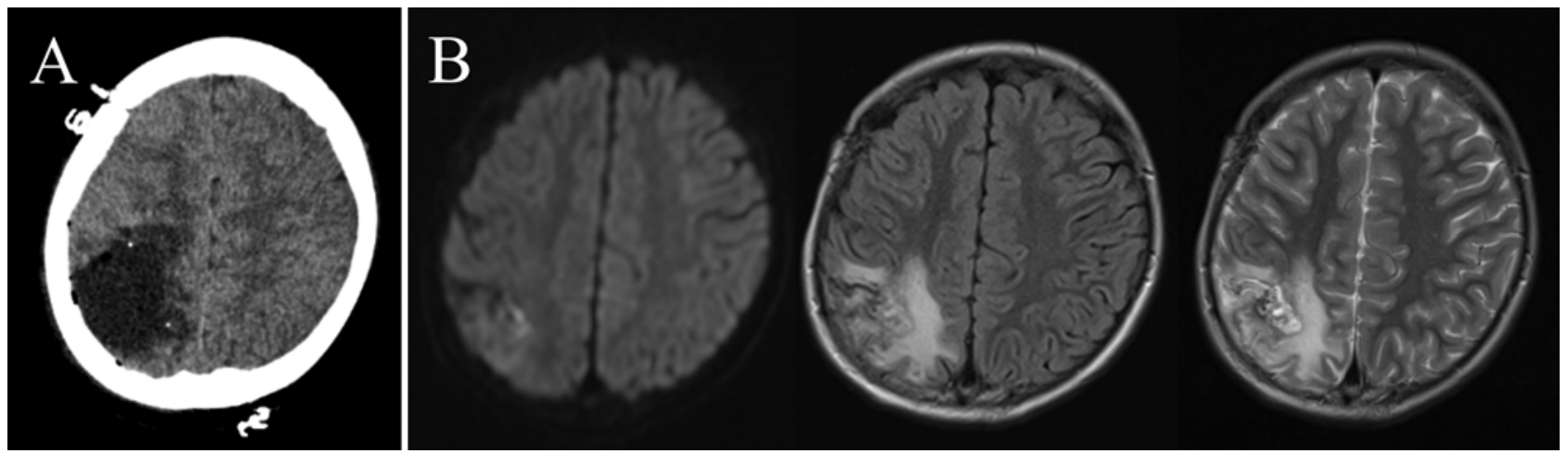

FIG. 3. Postoperative imaging. A: Postoperative CT image. B: Postoperative MR images showing total removal of the nidus with surrounding edema (diffusion-weighted image [left]; fluid-attenuated inversion recovery image [center]; and T2-weighted image [right]). 


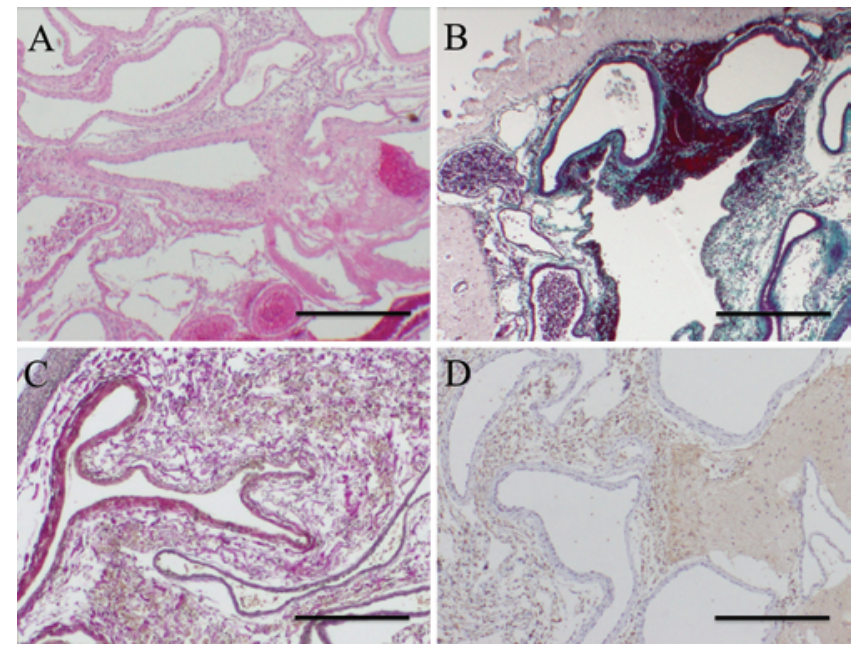

FIG. 4. Pathological findings were typical of cerebral AVM. $H$ \& $E(A)$, elastica-Masson (B), elastica-van Gieson (C), and VEGF (D), bar = 50 $\mu \mathrm{m}$. Figure is available in color online only.

and previous reports (Table 2), 1,3,4,6,9-11,14,16,19,22-28,30,32,34,36 it is likely that AVMs are not exclusively congenital in origin. That is, AVMs possess dynamic pathophysiological features with the potential for growth and de novo formation. . $3,4,6,9-11,13,14,16,19,22-28,30,32,34,36^{2}$
A total of 22 patients (including our patient) with de novo AVMs have been reported (Table 2). The majority of these patients were young, and the diagnosis was usually established during childhood. Of the 22 cases, hemorrhagic lesions such as subarachnoid hemorrhages or subdural hematomas were detected in $8(36.4 \%)$ patients. A retrospective review of the imaging in these cases did not reveal any flow voids or areas of focal edema; therefore, hematoma-induced mass effect, vasospasm, or partial thrombosis concealed the AVM. Other common features included seizure in $5(22.7 \%)$ patients and headache in 4 $(18.2 \%)$ patients.

The previous reports (Table 2) suggest 2 potential hypotheses for the apparent de novo development in our patient. One hypothesis is that the lesions were too small to detect at the first imaging and that some growth factors made the lesions expand in the intervening period to the index presentation. The other possibility is that abnormal flow dynamics were induced by a nidus or drainer thrombosis, whereas our patient showed no mass effect or vasospasm.

We report here the case of a 5-year-old child with a family history of HHT in whom a cerebral AVM was detected after an episode of thunderclap headache; MRI did not reveal the lesion in his infancy. To our knowledge, this is the first report of de novo AVM in a patient with

TABLE 2. Literature review of de novo cerebral AVM cases

\begin{tabular}{|c|c|c|c|c|c|c|c|c|c|}
\hline \multirow[b]{2}{*}{ Authors \& Year } & \multirow[b]{2}{*}{ Sex } & \multicolumn{3}{|c|}{ Initial Imaging Study } & \multicolumn{4}{|c|}{ Follow-Up Imaging Study } & \multirow[b]{2}{*}{ Interval (yrs) } \\
\hline & & Age (yrs) & Modality & Reason & Age (yrs) & Modality & Reason & AVM Location & \\
\hline Porter \& Bull, 1969 & M & 22 & DSA & $\mathrm{SAH}$ & 24 & DSA & $\mathrm{SAH}$ & Rt PCA territory & 2 \\
\hline Krayenbühl, 1977 & M & 3 & DSA & SAH & 12 & DSA & $\mathrm{SAH}$ & Rt frontal & 9 \\
\hline Watanabe et al., 1977 & M & 7 & DSA & $\mathrm{CSDH}$ & 20 & DSA & $\mathrm{HA}$ & Lt frontal & 13 \\
\hline Peeters, 1982 & $\mathrm{M}$ & 3 & DSA & $\mathrm{SAH}$ & 26 & DSA & Seizure & Rt frontal & 23 \\
\hline Mendelow et al., 1987 & $\mathrm{~F}$ & NA & DSA & SAH & NA & DSA & SAH & Rt occipital & 12 \\
\hline Morioka et al., 1988 & M & 15 & DSA & SAH & 23 & DSA & Seizure & Lt frontal & 8 \\
\hline Isayama et al., 1991 & M & 18 & DSA & $\mathrm{ICH}$ & 20 & DSA & $\mathrm{ICH}$ & Lt temporal & 2 \\
\hline Schmit et al., 1996 & M & 2 & DSA & Seizure & 11 & DSA & Follow-up & Lt parietal & 9 \\
\hline Nussbaum et al., 1998 & M & 24 & DSA & $\mathrm{HA}$ & 34 & DSA & Recurrent HA & Rt cerebellar & 10 \\
\hline Freidman et al., 2000 & M & 61 & DSA & Vertigo & 63 & DSA & Follow-up & Vermis & 2 \\
\hline Harris et al., 2000 & M & 57 & DSA & $\mathrm{HA}$ & 57 & DSA & Follow-up & Rt occipital & $6^{*}$ \\
\hline Rodríguez-Arias et al., 2000 & $\mathrm{~F}$ & 9 & DSA & Seizure & 11 & DSA & Follow-up & Rt parietal & 2 \\
\hline Bulsara et al., 2002 & $\mathrm{~F}$ & 26 & DSA & Infection & 32 & DSA & $\mathrm{HA}$ & Rt temporal & 6 \\
\hline Akimoto et al., 2003 & $\mathrm{~F}$ & 10 & DSA & IVH & 27 & DSA & IVH & Lt occipital & 17 \\
\hline Miyasaka et al., 2003 & $\mathrm{~F}$ & 50 & DSA & $\mathrm{HA}$ & 58 & DSA & $\mathrm{SAH}$ & Rt parietal & 8 \\
\hline Gonzalez et al., 2005 & $\mathrm{~F}$ & 3 & MRI & Seizure & 7 & MRI & Epilepsy & Rt temporal & 4 \\
\hline O'Shaughnessy et al., 2005 & $\mathrm{~F}$ & 6 & MRI & $S C D$ & 6 & DSA & Examination & Rt sylvian fissure & Immediately \\
\hline Mahajan et al., 2010 & $\mathrm{~F}$ & 16 & MRI & Bell's palsy & 30 & MRI & Migraine/seizure & Lt frontoparietal & 14 \\
\hline Stevens et al., 2009 & $\mathrm{~F}$ & 6 & MRI & Seizure & 9 & MRI & Seizure & Lt temporooccipital & 3 \\
\hline Alvarez et al., 2012 & M & 6 & MRI & Seizure & 8 & MRI & Follow-up & Rt temporooccipital & 2 \\
\hline Kilbourn et al., 2014 & M & 11 & MRI & Post-VPS & 18 & DSA & $\mathrm{HA}$ & Brainstem & 7 \\
\hline Present study & M & $5 \dagger$ & MRI & Screening & 5 & DSA & $\mathrm{HA}$ & Rt parietal & 5 \\
\hline
\end{tabular}

$\mathrm{CSDH}=$ chronic subdural hematoma; $\mathrm{HA}=$ headache; $\mathrm{ICH}=$ intracerebral hemorrhage; $\mathrm{IVH}=$ intraventricular hemorrhage; $\mathrm{NA}=$ not available; $\mathrm{PCA}=$ posterior cerebral artery; $\mathrm{SAH}=$ subarachnoid hemorrhage; SCD = sickle cell disease; VPS ventriculoperitoneal shunt.

* This interval is expressed in weeks.

$\dagger$ This age is expressed in months. 
HHT, although Komiyama ${ }^{15}$ mentioned the possibility that human cerebral AVMs could form until 2 years of age. AVMs seem to be dynamic conditions; in some cases they enlarge, whereas in others they regress or disappear (see Table 2). Previous reports have emphasized the need for repeated DSA in cases of childhood HHT, even if the first screening MRI results were negative. ${ }^{17}$ However, there is currently no consensus on an adequate period of time between the first and second screenings. Considering this case, we recommend that an annual screening MRI be performed. In patients with a family history of HHT, de novo AVMs are possible, even when no lesions are detected at the first screening. Therefore, regular screenings need to be performed, and the family should be informed that AVMs can still develop despite normal MRI results.

\section{Acknowledgments}

We thank Ms. Rika Nagashima for her technical assistance.

\section{References}

1. Akimoto H, Komatsu K, Kubota Y: Symptomatic de novo arteriovenous malformation appearing 17 years after the resection of two other arteriovenous malformations in childhood: case report. Neurosurgery 52:228-232, 2003

2. Al-Saleh S, Mei-Zahav M, Faughnan ME, MacLusky IB, Carpenter S, Letarte M, et al: Screening for pulmonary and cerebral arteriovenous malformations in children with hereditary haemorrhagic telangiectasia. Eur Respir J 34:875-881, 2009

3. Alvarez H, Perry V, Solle M, Castillo M: De novo cerebral arteriovenous malformation in a child with previous cavernous malformation and developmental venous anomaly. $\mathbf{J}$ Neurosurg Pediatr 9:327-330, 2012

4. Bulsara KR, Alexander MJ, Villavicencio AT, Graffagnino C: De novo cerebral arteriovenous malformation: case report. Neurosurgery 50:1137-1141, 2002

5. Du R, Hashimoto T, Tihan T, Young WL, Perry V, Lawton MT: Growth and regression of arteriovenous malformations in a patient with hereditary hemorrhagic telangiectasia. Case report. J Neurosurg 106:470-477, 2007

6. Friedman JA, Pollock BE, Nichols DA: Development of a cerebral arteriovenous malformation documented in an adult by serial angiography. Case report. J Neurosurg 93:10581061,2000

7. Fulbright RK, Chaloupka JC, Putman CM, Sze GK, Merriam MM, Lee GK, et al: MR of hereditary hemorrhagic telangiectasia: prevalence and spectrum of cerebrovascular malformations. AJNR Am J Neuroradiol 19:477-484, 1998

8. Giordano P, Nigro A, Lenato GM, Guanti G, Suppressa P, Lastella P, et al: Screening for children from families with Rendu-Osler-Weber disease: from geneticist to clinician. J Thromb Haemost 4:1237-1245, 2006

9. Gonzalez LF, Bristol RE, Porter RW, Spetzler RF: De novo presentation of an arteriovenous malformation. Case report and review of the literature. J Neurosurg 102:726-729, 2005

10. Harris OA, Chang SD, Harris BT, Adler JR: Acquired cerebral arteriovenous malformation induced by an anaplastic astrocytoma: an interesting case. Neurol Res 22:473-477, 2000

11. Isayama Y, Nakagawara J, Takeda R, Wada K, Hyogo T, Sasaki T, et al: [A case of cerebral arteriovenous malformation revealed at repeated subcortical hematoma with initially normal angiogram.] No Shinkei Geka 19:1175-1180, 1991 (Jpn)

12. Johnson DW, Berg JN, Baldwin MA, Gallione CJ, Marondel I, Yoon SJ, et al: Mutations in the activin receptor-like kinase
1 gene in hereditary haemorrhagic telangiectasia type 2. Nat Genet 13:189-195, 1996

13. Kader A, Goodrich JT, Sonstein WJ, Stein BM, Carmel PW, Michelsen WJ: Recurrent cerebral arteriovenous malformations after negative postoperative angiograms. J Neurosurg 85:14-18, 1996

14. Kilbourn KJ, Spiegel G, Killory BD, Kureshi I: Case report of a de novo brainstem arteriovenous malformation in an 18 -year-old male and review of the literature. Neurosurg Rev 37:685-691, 2014

15. Komiyama M: Revised perspective of cerebral arteriovenous malformation. Jpn J Neurosurg (Tokyo) 20:4-11, 2011

16. Krayenbühl HA: Angiographic contribution to the problem of enlargement of cerebral arteriovenous malformations. Acta Neurochir (Wien) 36:215-242, 1977

17. Latino GA, Al-Saleh S, Carpenter S, Ratjen F: The diagnostic yield of rescreening for arteriovenous malformations in children with hereditary hemorrhagic telangiectasia. J Pediatr 165:197-199, 2014

18. Leung KM, Agid R, terBrugge K: Spontaneous regression of a cerebral arteriovenous malformation in a child with hereditary hemorrhagic telangiectasia. Case report. J Neurosurg 105 (5 Suppl):428-431, 2006

19. Mahajan A, Manchandia TC, Gould G, Bulsara KR: De novo arteriovenous malformations: case report and review of the literature. Neurosurg Rev 33:115-119, 2010

20. Maher CO, Piepgras DG, Brown RD Jr, Friedman JA, Pollock BE: Cerebrovascular manifestations in 321 cases of hereditary hemorrhagic telangiectasia. Stroke 32:877-882, 2001

21. McAllister KA, Grogg KM, Johnson DW, Gallione CJ, Baldwin MA, Jackson CE, et al: Endoglin, a TGF-beta binding protein of endothelial cells, is the gene for hereditary haemorrhagic telangiectasia type 1. Nat Genet 8:345-351, 1994

22. Mendelow AD, Erfurth A, Grossart K, Macpherson P: Do cerebral arteriovenous malformations increase in size? J Neurol Neurosurg Psychiatry 50:980-987, 1987

23. Miyasaka Y, Nakahara K, Takagi H, Hagiwara H: Development of multiple cerebral arteriovenous malformations documented in an adult by serial angiography. Case report. J Neurosurg 98:190-193, 2003

24. Morioka T, Nishio S, Hikita T, Chung LH, Soejima T: Marked growth of an angiographically occult arteriovenous malformation: case report. Neurosurgery 23:101-103, 1988

25. Nussbaum ES, Heros RC, Madison MT, Awasthi D, Truwit CL: The pathogenesis of arteriovenous malformations: insights provided by a case of multiple arteriovenous malformations developing in relation to a developmental venous anomaly. Neurosurgery 43:347-352, 1998

26. O'Shaughnessy BA, DiPatri AJ Jr, Parkinson RJ, Batjer HH: Development of a de novo cerebral arteriovenous malformation in a child with sickle cell disease and moyamoya arteriopathy. Case report. J Neurosurg 102 (2 Suppl):238-243, 2005

27. Peeters FL: Angiographically demonstrated larger vascular malformation in a patient with a normal angiogram 23 years before. Neuroradiology 23:113-114, 1982

28. Porter AJ, Bull J: Some aspects of the natural history of cerebral arteriovenous malformation. Br J Radiol 42:667-675, 1969

29. Pozzati E, Giangaspero F, Marliani F, Acciarri N: Occult cerebrovascular malformations after irradiation. Neurosurgery 39:677-684, 1996

30. Rodríguez-Arias C, Martínez R, Rey G, Bravo G: Recurrence in a different location of a cerebral arteriovenous malformation in a child after radiosurgery. Childs Nerv Syst 16:363-365, 2000

31. Sasamori T, Hida K, Asano T, Nakayama N, Kuroda S, 
Iwasaki Y: [High-flow arteriovenous fistula of the central nervous system associated with hereditary haemorrhagic telangiectasia.] No Shinkei Geka 37:57-63, 2009 (Jpn)

32. Schmit BP, Burrows PE, Kuban K, Goumnerova L, Scott RM: Acquired cerebral arteriovenous malformation in a child with moyamoya disease. Case report. J Neurosurg 84:677-680, 1996

33. Song JK, Niimi Y, Kupersmith MJ, Berenstein A: Postnatal growth and development of a cerebral arteriovenous malformation on serial magnetic resonance imaging in a child with hemangiomatosis. Case report. J Neurosurg 106 (5 Suppl):384-387, 2007

34. Stevens J, Leach JL, Abruzzo T, Jones BV: De novo cerebral arteriovenous malformation: case report and literature review. AJNR Am J Neuroradiol 30:111-112, 2009

35. Sugiyama T, Nakayama N, Terasaka S, Kuroda S, Houkin $\mathrm{K}$ : Giant calcified thrombosed varices secondary to a pial arteriovenous fistula associated with hereditary hemorrhagic telangiectasia. Neurol Med Chir (Tokyo) 52:506-509, 2012

36. Watanabe E, Nagamune A, Masuzawa H, Sano K: [A case of cerebral arteriovenous malformation with presented remarkable enlargement during 13 years.] No To Shinkei 29:12851289,1977 (Jpn)
37. Xu B, Wu YQ, Huey M, Arthur HM, Marchuk DA, Hashimoto T, et al: Vascular endothelial growth factor induces abnormal microvasculature in the endoglin heterozygous mouse brain. J Cereb Blood Flow Metab 24:237-244, 2004

\section{Disclosures}

The authors report no conflict of interest concerning the materials or methods used in this study or the findings specified in this paper.

\section{Author Contributions}

Conception and design: Shimoda. Acquisition of data: Shimoda. Drafting the article: Shimoda. Critically revising the article: all authors. Approved the final version of the manuscript on behalf of all authors: Shimoda.

\section{Correspondence}

Yusuke Shimoda, Department of Neurosurgery, Hokkaido University Graduate School of Medicine, North 15 West 7, Kita-ku, Sapporo Hokkaido 060-8638, Japan.email: shimoda-hok@umin. ac.jp. 